\title{
Deposição de glyphosate com diferentes pontas de pulverização na dessecação de plantas de Panicum maximum ${ }^{1}$
}

\section{Glyphosate deposition with different aprayer nozzles in burndown of Panicum maximum plants}

\author{
Neumárcio Vilanova da Costa ${ }^{2 *}$, Dagoberto Martins ${ }^{3}$, Andréia Cristina Peres Rodrigues da \\ Costa $^{4}$, Leonildo Alves Cardoso ${ }^{5}$
}

Resumo - Objetivou-se com este trabalho avaliar a deposição de uma solução traçante constituída de glyphosate $\left(2.160 \mathrm{~g} \mathrm{ha}^{-1}\right)+$ corante FD\&C n ${ }^{\circ} 1(2.000 \mathrm{ppm})$ com diferentes pontas de pulverização na dessecação de plantas de Panicum maxicum cv. Mombaça, além da quantificação das perdas da calda de pulverização para o solo. O delineamento experimental foi o de blocos casualizados, com quatro repetições. Cada unidade experimental constituiu-se de três linhas de 5,0 m de comprimento, espaçadas de 1,0 m. A aplicação dos tratamentos foi realizada 12 meses após a semeadura do capim-colonião; 40 dias antes da aplicação foi realizada uma roçagem para uniformização da área. Foram avaliadas as pontas de pulverização de jato plano XR 110.015 VS (100 L ha $\left.{ }^{-1}\right)$ e XR 110.02 VS (200 L ha $\left.{ }^{-1}\right)$, jato cônico TX-4VS $\left(100 \mathrm{~L} \mathrm{ha}^{-1}\right)$ e TX-8 VK (200 L ha $\left.{ }^{-1}\right)$, ponta com indução de ar AI 11002 VS $\left(200 \mathrm{~L} \mathrm{ha}^{-1}\right)$ e jato plano duplo TJ60 11002 VS (200 L ha $\left.{ }^{-1}\right)$. Imediatamente após a aplicação, foram coletados 25 perfilhos por repetição, sendo lavados separadamente as folhas e caules de cada perfilho em $150 \mathrm{~mL}$ de água destilada, para posterior quantificação do traçador em espectrofotômetro. Os dados foram ajustados à curva de regressão pelo modelo de Gompertz. Todos os tratamentos foram eficientes na dessecação das plantas de P. maximum, independentemente da ponta e volume utilizado, o que evidencia a possibilidade de redução do volume de aplicação e da dosagem do herbicida na dessecação de plantas de capim-colonião, considerando-se a utilização de herbicidas sistêmicos. Ressalta-se que houve diferença na quantidade e uniformidade de distribuição da calda pulverizada nos alvos avaliados em função da ponta testada e, consequentemente, do volume utilizado. A ponta TX-8 VK $\left(200 \mathrm{~L} \mathrm{ha}^{-1}\right)$, proporcionou menor deposição de calda no solo.

Palavras chaves: Controle químico; tecnologia de aplicação; traçador, forrageira.

\footnotetext{
* Autor para correspondência

${ }^{1}$ Recebido para publicação em 30/09/2011 e aceito 10/02/2012.

2 Professor Adjunto, UNIOESTE/CCA, Caixa Postal 91, 85960-000, Marechal Cândido Rondon-PR, Email: neumarciovc@hotmail.com;

${ }^{3}$ Professor Adjunto, Dep. de Produção Vegetal, Faculdade de Ciências Agronômicas - FCA/UNESP, Fazenda Lageado, Caixa Postal 237, 18603-970 Botucatu-SP;

${ }^{4}$ Bolsista Pós-Doutorado, UNIOESTE/CCA, Marechal Cândido Rondon-PR;

${ }^{5}$ Engenheiro Agrônomo, Doutor, Organização das Nações Unidas para Agricultura e Alimentação - FAO, GuinéBissau, África;
} 
Abstract - The objective of this work was to evaluate the deposition of a tracer solution constituted by glyphosate $\left(2,160 \mathrm{~g} \mathrm{ha}^{-1}\right)+\mathrm{FD} \& \mathrm{C} \mathrm{N}$. 1 (2,000 ppm) blushing with different sprayer nozzles in burndown of Panicum maximum cv. Mombaça plants, besides the losses quantification of the sprayer to the soil. A randomized complete block design was used with four replications. Each experimental unit consisted of three lines with $5 \mathrm{~m}$ long, spiced of $1.0 \mathrm{~m}$. Treatments were applied 12 months after $P$. maximum seeding, and 40 days before application, a cut was conducted to become the area uniform. The following sprayer nozzles were evaluated: fat flan nozzle XR $110015 \mathrm{VS}\left(100 \mathrm{~L} \mathrm{ha}^{-1}\right)$ and XR $11002 \mathrm{VS}\left(200 \mathrm{~L} \mathrm{ha}^{-1}\right)$, cone nozzle TX-4 VS $\left(100 \mathrm{~L} \mathrm{ha}^{-1}\right)$ and TX-8 VK $\left(200 \mathrm{~L} \mathrm{ha}^{-1}\right)$, air induction nozzle AI $11002 \mathrm{VS}\left(200 \mathrm{~L} \mathrm{ha}^{-1}\right)$ and double flat fan nozzle TJ $6011002 \mathrm{VS}\left(200 \mathrm{~L} \mathrm{ha}^{-1}\right)$. Immediately after application, 25 tillers per replication were collected and washed separately leaves and stem of each one in $150 \mathrm{ml}$ of distilled water, for later quantification of the tracer in a spectrophotometer. Obtained data were adjusted to a regression curve by Gompertz model. All treatments were effective in burndown $P$. maximum plants, independently of the spray nozzles or used volume used, which suggests the possibility of reducing application volume and herbicide dosage in burndown desiccation the studied specie, considering the use of systemic herbicide. However, there was difference in the quantity, as well as in the uniformity of solution distribution sprayed in the evaluated targets in relation to spray nozzles used, and consequently of used volume. The cone nozzle TX-VK 8 (200 $\mathrm{L} \mathrm{ha}^{-1}$ ), provided less spray deposition on the soil.

Key words: chemical control; technology of application; tracer and forage.

\section{Introdução}

A dessecação da cobertura vegetal para o plantio direto pode ser feita com os herbicidas glyphosate, sulphosate, diquat e paraquat (Kozlowski, 2001). Contudo, em espécies daninhas semi perenes e perenes, os herbicidas de ação de contato não têm apresentado boa eficácia, podendo ocorrer rebrotas e, consequente, reinfestação da área.

O glyphosate é um herbicida aplicado em pós-emergência, sistêmico, absorvido por via foliar e translocado até as raízes. Sua eficácia é dependente de processos como a retenção da molécula na superfície foliar, a penetração foliar, a translocação na planta até o sítio de ação e a inibição da enzima-alvo, a 5enolpiruvilshiquimato-3-P-sintetase (EPSPs). Promove a morte total das plantas daninhas e a não-ocorrência de rebrota através da inibição da atividade enzimática, da redução da síntese de proteínas, do aumento da taxa de respiração, da inibição lenta da fotossíntese, rápida da inibição da transpiração e do aumento na produção de etileno (Rodrigues \& Almeida, 2005)

Diversos trabalhos têm sido realizados quanto à hipótese do tamanho da gota produzida afetar ou não a eficácia do glyphosate. Venturelli et al. (2006), trabalhando com diferentes tamanhos de gotas para aplicação de glyphosate, verificaram maior eficácia do glyphosate quando as gotas produzidas possuíam diâmetros superiores a $250 \mu \mathrm{m}$, provavelmente devido ao fato de gotas pequenas terem sido acometidas por deriva. Já Costa et al. (2008), avaliaram a eficácia do glyphosate aplicado com diversos diâmetros de gotas e volumes de calda de 100 a $200 \mathrm{~L} \mathrm{ha}^{-1}$ na dessecação de Brachiaria brizantha, observaram que todas as condições de aplicações foram eficientes, o que evidencia a possibilidade de redução do volume de aplicação e dosagem do herbicida.

$\mathrm{O}$ incremento de controle das plantas daninhas para uma mesma dosagem do produto 
resulta em melhor aproveitamento do herbicida, o que é desejável do ponto de vista ambiental (Agairupdate, 2000). Para se obter melhores resultados no controle de plantas daninhas, além de estudar fatores inerentes às espécies a serem controladas, é imprescindível também estudar fatores inerentes à aplicação. Entre esses fatores destacam-se o tamanho e a densidade de gotas, as perdas para o solo e por deriva, o equipamento, o volume de calda e as pontas de pulverização, sendo a seleção correta das pontas de pulverização, uma forma de se obter maior deposição do ingrediente ativo sobre os alvos biológicos (Souza et al., 2007; Viana et al., 2007; Souza et al., 2012).

Segundo Venturelli et al. (2006), gotas uniformes normalmente proporcionam maior eficiência biológica por transportar, aproximadamente, a mesma concentração do produto por gota, o que contribui para absorção mais uniforme do ingrediente ativo. A distribuição da calda de pulverização no alvo de maneira desuniforme e abaixo do volume mínimo exigido resulta em controle ineficiente. Todavia, volumes acima do exigido podem causar toxidez nas culturas e contaminação ao ambiente (Cordeiro, 2001).

Ao considerar a dificuldade de controle de plantas daninhas perenizadas, mesmo utilizando-se de herbicidas não seletivos, surge a hipótese de que melhores resultados de controle podem ser obtidos se os produtos forem depositados no alvo de maneira uniforme. Para averiguar a veracidade dessa hipótese, objetivou-se com o trabalho avaliar a deposição de glyphosate com diferentes pontas de pulverização na dessecação de plantas de Panicum maxicum cv. Mombaça, assim como as perdas da calda de pulverização para o solo.

\section{Material e Métodos}

O trabalho foi instalado à campo com plantas perenizadas de $P$. maximum $\mathrm{cv}$.
Mombaça. A área experimental possui solo argiloso, classificado como NITOSSOLO VERMELHO Estruturado, e encontra-se localizada a $762 \mathrm{~m}$ de altitude.

As plantas de $P$. maximum foram semeadas em 18/03/2004, utilizando-se linhas espaçadas de $1,0 \mathrm{~m}$. No dia 13/02/2005 as plantas foram roçadas, para uniformização da área, e quarenta dias após apresentavam-se com altura entre 40 a $60 \mathrm{~cm}$, ocasião da qual ocorreu a instalação do experimento (23/03/2005). O delineamento experimental utilizado foi de blocos casualizados, com seis tratamentos e quatro repetições (Tabela 1). Cada unidade experimental foi constituída por três linhas de capim-colonião com 5,0 m de comprimento. $\mathrm{Na}$ calda de aplicação do herbicida glyphosate, na dose de 2.160 g e. a ha ${ }^{-1}$, foi acrescida um traçador composto pelo corante alimentício Azul Brilhante (FD\&C no1), na concentração de $2.000 \mathrm{ppm}$, conforme metodologia descrita por Palladini et al. (2005).

As condições climáticas durante a aplicação variaram de 24,5 a $31,8{ }^{\circ} \mathrm{C}$ de temperatura do ar, 62 a $80 \%$ de umidade relativa e rajadas de ventos de aproximadamente $3,6 \mathrm{~km} \mathrm{~h}^{-1}$. O herbicida foi aplicado utilizando-se pulverizador costal pressurizado a $\mathrm{CO}_{2}$ e equipado com reservatório de 10 litros, e barra de aplicação com seis pontas, espaçadas em $50 \mathrm{~cm}$ entre si.

Os efeitos da dessecação das plantas de capim-colonião foram avaliados visualmente aos 4, 11, 17, 26 e 30 dias após aplicação (DAA) do herbicida, por meio de escala percentual de notas, na qual $0 \%$ correspondeu a nenhuma injúria visível nas plantas e $100 \%$, à morte das plantas (SBCPD, 2000). Os indicadores utilizados para o estabelecimento das notas foram: inibição do crescimento, quantidade e uniformidade das injúrias, capacidade de rebrota das plantas, quantidade de plantas mortas e acúmulo de biomassa. Aos 30 DAA, também foi avaliada a matéria seca 
das plantas, utilizando-se como unidade amostral um quadro $(0,5 \times 0,5 \mathrm{~m})$, o qual foi lançado aleatoriamente dentro de cada parcela e coletando as plantas na área do referido quadro.

Para avaliar o processo de aplicação do herbicida glyphosate, foi conduzido o estudo de deposição da calda nas plantas de capimcolonião e as perdas para o solo. Para isso, foram coletadas imediatamente após a aplicação da calda, 25 perfilhos por repetição, que após separadas as folhas e caules foram acondicionados em sacos plásticos. Para determinação da quantidade de herbicida + traçador depositado sobre o solo, foram utilizadas caixas plásticas tipo Gerbox $(11,5 \mathrm{x}$ $11,5 \times 3,0 \mathrm{~cm})$, sendo estas distribuídas antes da aplicação, posicionando 4,0 caixas nas entrelinhas e 4,0 caixas nas linhas da cultura. No laboratório, lavou-se as caixas plásticas e cada parte da planta com $150 \mathrm{~mL}$ de água destilada, que foi utilizada para quantificar a concentração do corante Azul Brilhante, através da determinação da densidade óptica (absorbância $=630 \mathrm{~nm})$ das soluções, através de espectrofotômetro de UV visível GBC, modelo Cintra 20.

Após a lavagem, as partes das plantas foram acondicionadas em sacos de papel etiquetados e, mantidas em estufa de ventilação forçada de ar para secagem durante 72 horas em temperatura de $60^{\circ} \mathrm{C}$, para posterior pesagem e determinação da matéria seca.

Tabela 1 - Tratamentos utilizados no estudo da dessecação de plantas de Panicum maximum cv. Mombaça.

\begin{tabular}{|c|c|c|c|}
\hline Tratamentos & $\begin{array}{l}\text { Volume } \\
\left(\mathrm{L} \mathrm{ha}^{-1}\right)\end{array}$ & $\begin{array}{c}\text { Pressão } \\
\text { (kPa) }\end{array}$ & $\begin{array}{c}\text { Classificação } \\
\text { das gotas }\end{array}$ \\
\hline XR $11001 \mathrm{VS}$ & $100^{-}$ & 160 & Fina \\
\hline $\mathrm{XR} 11002 \mathrm{VS}$ & 200 & 210 & Fina \\
\hline TX-4 VS & 100 & 350 & Muito Fina \\
\hline TX-8 VK & 200 & 450 & Muito Fina \\
\hline AI 11002 VS & 200 & 200 & $\begin{array}{c}\text { Extremamente } \\
\text { Grossa }\end{array}$ \\
\hline TJ601002 VS & 200 & 190 & Fina \\
\hline
\end{tabular}

Os dados obtidos dos depósitos em porcentagem foram ajustados pelo modelo de Gompertz $\left(F A=e^{a-e^{-b-c * x}}\right)$, para representar a frequência acumulada (FA) da deposição da calda pulverizada. Adotou-se o valor 4,60517 para o parâmetro "a" do modelo, o qual representa a assíntota máxima da curva, em que "e $\mathrm{e}^{\mathrm{a} "}=100$, conforme o modelo ajustado por Velini (1995). O deslocamento da curva ao longo do eixo x é representado pelo módulo do parâmetro "a", e a inclinação ou concavidade da curva em relação a frequência acumulada, pelo parâmetro "c". Além disso, para melhor visualização, optou-se por apresentar as frequências não-acumuladas (FNA) $\left(F N A=c * e^{a-b-c * x-e^{-b-c * x}}\right), \quad$ que correspondem a derivada da primeira do modelo. As frequências acumuladas e nãoacumuladas do modelo de Gompertz permitem a interpretação biológica dos resultados. Para facilitar a visualização das informações, a derivada primeira corresponde à moda da deposição da solução pulverizada nos alvos específicos (Velini, 1995).

Os valores de média, moda e mediana também foram estabelecidos no trabalho. A precisão do ajuste dos dados do modelo de Gompertz foi avaliada por meio dos coeficientes de determinação $\left(\mathrm{R}^{2}\right)$ e pela soma dos quadrados dos resíduos das equações.

Os resultados foram submetidos à análise de variância pelo Teste $\mathrm{F}$, sendo que os valores, em porcentagem, foram transformados em arco seno $\sqrt{ } \mathrm{x} / 100$ e as médias comparadas pelo Teste "LSD" ( $p>0,05)$.

\section{Resultados e discussão}

As pontas TJ60 11002 VS e AI 11002 VS, ambas no volume de calda de $200 \mathrm{~L} \mathrm{ha}^{-1}$, foram as que resultaram em maior porcentagem de depósitos que atingiram o solo, com 26,91 e $26,21 \%$, respectivamente (Tabela 2 ). A ponta TX-8 VK foi a que obteve menor depósito no 
solo, com 11,08\% do volume pulverizado. Esses resultados são importantes para a aplicação de herbicidas em pós-emergência em pastagens, que possuam efeito residual no solo, pois poderão promover também o controle em pré-emergência. Esses dados também podem ser extrapolados para aplicações de inseticidas, no controle da cigarrinha da pastagem, conforme Maciel et al. (2007).

Tabela 2 - Porcentagem de depósitos da calda de pulverização que alcançaram o solo durante a dessecação de plantas de Panicum maximum cv. Mombaça.

\begin{tabular}{|c|c|c|}
\hline Tratamentos & Volume (L ha $\left.{ }^{-1}\right)$ & Calda (\%) \\
\hline XR 11001 VS & 100 & $20,83 \mathrm{ab}$ \\
\hline $\mathrm{XR} 11002 \mathrm{VS}$ & 200 & $22,10 \mathrm{a}$ \\
\hline $\mathrm{TX}-\overline{4} \overline{\mathrm{V}} \overline{\mathrm{S}}$ & 100 & $18,27 \mathrm{ab}$ \\
\hline TX-8 VK & $\begin{array}{r}200 \\
200\end{array}$ & $=\frac{11,08 \mathrm{~b}}{26,21 \mathrm{a}}$ \\
\hline TJ60 $11002 \mathrm{VS}$ & 200 & $26,91 \mathrm{a}$ \\
\hline$F_{\text {Tratamento }}$ & & $\overline{\mathrm{P}}<\overline{0}, 001$ \\
\hline CV (\%) & & 20,38 \\
\hline d.m.s. & & 9,79 \\
\hline
\end{tabular}

Dados de porcentagem foram transformados em arco seno $\sqrt{ } \mathrm{x} / 100$. Médias seguidas de mesma letra na coluna, não diferem estatisticamente entre si, pelo teste "LSD" $(\mathrm{p}>0,05){ }^{\text {ns }}$ - não significativo.
Souza et al (2012), avaliando a deposição de 2,4-D Amina com diferentes pontas e volumes de pulverização em plantas daninhas, observaram maior perda de produto para o solo com o emprego das pontas de jato plano defletor com indução de ar, e menor com pontas de jato plano duplo de pré-orifício.

Observa-se na Figura 1 (A - B) e Tabela 3, a ponta TJ60 110.02 VS proporcionou maior deposição da calda de pulverização nas folhas, seguida por XR 110.02 VS, com valores da moda de 101,37 e $86,70 \mu \mathrm{L}$ $\mathrm{g}^{-1}$ de massa seca, respectivamente; ambas com volume de calda de $200 \mathrm{~L} \mathrm{ha}^{-1}$. A ponta TX-4 VS, que produz gotas muito finas, foi a que proporcionou a menor deposição, seguida pela XR $11001 \mathrm{VS}$, com valores da moda inferiores a 54,0 e 45,8\%, respectivamente, em relação à ponta TJ60 11002 VS. Resultados semelhantes foram relatados por Costa et al. (2008), em que as pontas TX-4 VS e XR 11001 VS, ambas em volume de $100 \mathrm{~L} \mathrm{ha}^{-1}$, proporcionaram os menores depósitos da calda de pulverização em plantas de Brachiaria brizantha.

Tabela 3 - Resultados das análises de regressão das frequências acumuladas dos depósitos da calda pulverizada em folhas de Panicum maximum cv. Mombaça, utilizando o modelo de Gompertz, bem como as médias, modas e medianas $\left(\mu \mathrm{L} \mathrm{g}^{-1}\right)$, das diferentes pontas de pulverização.

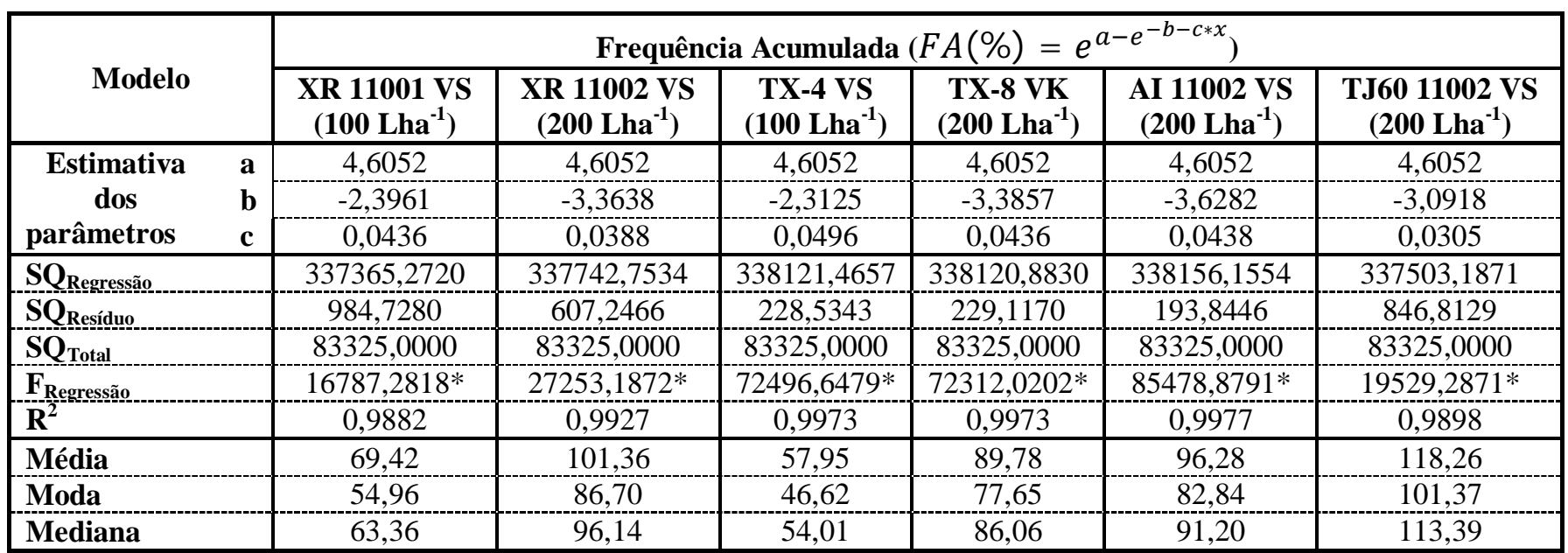

$\mathrm{X}=$ porcentagem de depósito do traçador em relação ao total aplicado; a, b e c são estimativas dos parâmetros do modelo para o traçador. $* *$ significativo a $1 \%$ de probabilidade. 
Por meio do parâmetro "c" do modelo de Gompertz (Tabela 3), cujos maiores valores indicam menores inclinações das curvas e maior uniformidade de deposição da calda de pulverização, pode-se verificar que a ponta TX-4 VS foi a que proporcionou maior uniformidade de distribuição das gotas em volume de $100 \mathrm{~L}$ ha $^{-1}$. Essa melhor distribuição pode ter ocorrido pelo fato dessa ponta produzir gotas de tamanho muito fino. A TJ60 110.02 VS foi a que promoveu menor valor para o parâmetro "c" (maior inclinação da curva). Entretanto, foi a que proporcionou a maior deposição de calda de pulverização nas folhas. Isto demonstra que nem sempre a ponta que resulta em maior deposição de calda é a que proporciona a melhor uniformidade de distribuição das gotas.

As pontas que se destacaram com as melhores uniformidades de deposição nas folhas de capim-colonião foram TX-4 VS, AI 11002 VS, TX-8 VK, no volume de $200 \mathrm{~L} \mathrm{ha}^{-1}$, e XR $11001 \mathrm{VS}$, com $100 \mathrm{~L} \mathrm{ha}^{-1}$ de calda (Figura $1 \mathrm{~A}$ B). A uniformidade da deposição da calda de pulverização destaca-se como fator importante no desempenho dos produtos fitossanitários, principalmente quando se considera produtos de ação de contato, que exigem maior área de cobertura do alvo.

Para os valores de deposição verificados nos caules das plantas de capimcolonião, as pontas AI 11002 VS e XR 11002 VS, com volume de calda $200 \mathrm{~L} \mathrm{ha}^{-1}$, proporcionaram os maiores valores da moda, o que indica maior deposição de gotas, sendo de 11,75 e $11,45 \mu \mathrm{L} \mathrm{g}^{-1}$ de massa seca, respectivamente (Tabela 4 ). $\mathrm{O}$ menor valor de depósitos médio foi verificado para a ponta XR 11001 VS com $100 \mathrm{~L} \mathrm{ha}^{-1}, 49,28 \%$ menor que o maior depósito médio registrado pela ponta AI 11002 VS. O fato da ponta AI 11002 VS ter promovido maior depósito médio, pode ser explicado pelo tamanho das gotas (grandes), que facilita a interceptação de partes do caule menos expostas e, ou por escorrimento das gotas depositadas na folha para o caule.

Tabela 4 - Resultados das análises de regressão das frequências acumuladas dos depósitos da calda pulverizada em caules de Panicum maximum cv. Mombaça, utilizando o modelo de Gompertz, bem como as médias, modas e medianas $\left(\mu \mathrm{L} \mathrm{g}^{-1}\right)$, das diferentes pontas de pulverização.

\begin{tabular}{|c|c|c|c|c|c|c|c|}
\hline \multirow{2}{*}{ Modelo } & & \multicolumn{6}{|c|}{ Frequiência Acumulada $\left(F A(\%)=e^{a-e^{-b-c * x}}\right)$} \\
\hline & & $\begin{array}{l}\text { XR 11001 VS } \\
\left(100 \text { Lha }^{-1}\right)\end{array}$ & $\begin{array}{c}\text { XR } 11002 \text { VS } \\
\left(200 \mathrm{Lha}^{-1}\right)\end{array}$ & $\begin{array}{c}\text { TX-4 VS } \\
\left(100 \text { Lha }^{-1}\right)\end{array}$ & $\begin{array}{c}\text { TX-8 VK } \\
\left(200 \text { Lha }^{-1}\right)\end{array}$ & $\begin{array}{c}\text { AI } 11002 \text { VS } \\
\left(200 \mathrm{Lha}^{-1}\right)\end{array}$ & $\begin{array}{c}\text { TJ60 11002 VS } \\
\left(200 \text { Lha }^{-1}\right)\end{array}$ \\
\hline \multirow{3}{*}{$\begin{array}{c}\begin{array}{c}\text { Estimativa } \\
\text { dos } \\
\text { parâmetros }\end{array} \\
\end{array}$} & & 4,6052 & 4,6052 & 4,6052 & 4,6052 & 4,6052 & 4,6052 \\
\hline & b & $-1,4262$ & $-1,6991$ & $-1,7487$ & $-1,5803$ & $-2,4763$ & $-1,9410$ \\
\hline & c & 0,2392 & 0,1484 & 0,2491 & 0,1864 & 0,2107 & 0,3086 \\
\hline $\mathbf{S Q}_{\text {Regressão }}$ & & 336433,6736 & 336884,8369 & 337523,4080 & 336378,9294 & 337730,6572 & 337849,9933 \\
\hline $\mathbf{S Q}_{\text {Resíduo }}$ & & 1916,3264 & 1465,1631 & 826,5920 & 1971,0706 & 619,3428 & 500,0067 \\
\hline $\mathbf{S Q}_{\text {Total }}$ & & 83325,0000 & 83325,0000 & 83325,0000 & 83325,0000 & 83325,0000 & 83325,0000 \\
\hline $\mathbf{F}_{\text {Regressão }}$ & & $8602,5277^{*}$ & $11266,5691 *$ & $20008,2403^{*}$ & $8362,2391 *$ & $26719,9586^{*}$ & $33108,8504 *$ \\
\hline $\mathbf{R}^{2}$ & & 0,9770 & 0,9824 & 0,9901 & 0,9763 & 0,9926 & 0,9940 \\
\hline Média & & 11,80 & 19,10 & 11,67 & 14,94 & 16,45 & 10,45 \\
\hline Moda & & 5,96 & 11,45 & 7,02 & 8,48 & 11,75 & 6,29 \\
\hline Mediana & & 7,49 & 13,92 & 8,49 & 10,44 & 13,49 & 7,48 \\
\hline
\end{tabular}

$\mathrm{X}=$ porcentagem de depósito do traçador em relação ao total aplicado; a, b e c são estimativas dos parâmetros do modelo para o traçador.** significativo a $1 \%$ de probabilidade. 
O tratamento que produziu os depósitos de calda mais uniformes foi o correspondente a ponta TJ60 11002 VS no volume de $200 \mathrm{~L} \mathrm{ha}^{-1}$. Porém, as pontas com depósitos de maior variação foram XR 11002 VS e TX-VK 8, ambas com $100 \mathrm{~L} \mathrm{ha}^{-1}$ (Figura $1 \mathrm{C}-\mathrm{D}$ e Tabela 4).

O volume aplicado numa pulverização deve ser o mais uniforme possível, sob pena de ser necessário volume adicional para compensar os pontos ou faixas que receberam menor quantidade de calda (Perecin et al., 1998). Galon et al. (2007) afirmam que a eficácia de controle das plantas daninhas, por herbicidas sistêmicos ou de contato, pode aumentar ou diminuir com a variação do volume de calda aplicado, demonstrando que a sensibilidade das infestantes aos herbicidas pode variar em função de fatores intrínsecos à espécie e do ambiente.

Ruas et al. (2011) concluíram que o melhor controle de Brachiara decumbens foi obtido quando se realizou a aplicação de glyphosate com menores diâmetros de gotas, distribuídas mais uniformemente sobre as folhas das plantas.

Na Figura 1 (E, F) e Tabela 5 estão representados os resultados obtidos para $\mathrm{O}$ perfilhos de capim-colonião (planta inteira). Com base nos valores de moda, a ponta TJ60 11002 VS proporcionou o maior depósito de calda de pulverização, seguida pela XR 11002 VS, ambas no volume de $200 \mathrm{~L} \mathrm{ha}^{-1}$. De forma contrária, as pontas TX-4 VS e XR 11001 VS, no volume de $100 \mathrm{~L} \mathrm{ha}^{-1}$, proporcionaram os menores depósitos de calda, com valores de $52,06 \%$ e $43,72 \%$ inferiores, respectivamente; em relação à TJ60 11002 VS. Ao comparar a uniformidade de distribuição, a ponta TX-4 VS com $100 \mathrm{~L} \mathrm{ha}^{-1}$ destacou-se das demais, com o melhor resultado. Além disso, a XR 11002 VS no volume de $200 \mathrm{~L} \mathrm{ha}^{-1}$ foi a mais desuniforme na deposição da calda.

Tabela 5 - Resultados das análises de regressão das frequências acumuladas dos depósitos da calda pulverizada em perfilho (planta inteira) de Panicum maximum cv. Mombaça, utilizando o modelo de Gompertz, bem como as médias, modas e medianas $\left(\mu \mathrm{L} \mathrm{g}^{-1}\right)$, das diferentes pontas de pulverização.

\begin{tabular}{|c|c|c|c|c|c|c|c|}
\hline \multirow{2}{*}{ Modelo } & & \multicolumn{6}{|c|}{ Frequiência Acumulada $\left(F A(\%)=e^{a-e^{-b-c * x}}\right)$} \\
\hline & & $\begin{array}{l}\text { XR 11001 VS } \\
\left(100 \mathrm{Lha}^{-1}\right)\end{array}$ & $\begin{array}{l}\text { XR } 11002 \text { VS } \\
\left(200 \mathrm{Lha}^{-1}\right)\end{array}$ & $\begin{array}{c}\text { TX-4 VS } \\
\left(100 \mathrm{Lha}^{-1}\right)\end{array}$ & $\begin{array}{c}\text { TX-8 VK } \\
\left(200 \text { Lha }^{-1}\right)\end{array}$ & $\begin{array}{c}\text { AI } 11002 \text { VS } \\
\left(200 \text { Lha }^{-1}\right)\end{array}$ & $\begin{array}{l}\text { TJ60 11002 VS } \\
\left(200 \mathrm{Lha}^{-1}\right)\end{array}$ \\
\hline \multirow{3}{*}{$\begin{array}{c}\text { Estimativa } \\
\text { dos } \\
\text { parâmetros }\end{array}$} & $\bar{a}$ & 4,6052 & 4,6052 & 4,6052 & 4,6052 & 4,6052 & 4,6052 \\
\hline & b & $-2,2192$ & $-3,1359$ & $-2,4394$ & $-3,2941$ & $-3,7935$ & $-3,3671$ \\
\hline & c & 0,0561 & 0,0471 & 0,0724 & 0,0591 & 0,0637 & 0,0479 \\
\hline & 337714,7130 & 338259,9203 & 338081,4872 & 338070,0447 & 337994,9867 & 337650,0394 \\
\hline \multicolumn{2}{|l|}{ SQResíduo } & 635,2870 & 90,0797 & 268,5128 & 279,9553 & 355,0133 & 699,9606 \\
\hline \multicolumn{2}{|l|}{$\mathbf{S Q}_{\text {Total }}$} & 83325,0000 & 83325,0000 & 83325,0000 & 83325,0000 & 83325,0000 & 83325,0000 \\
\hline \multicolumn{2}{|l|}{$\mathbf{F}_{\text {Regressão }}$} & $26048,1042 *$ & $184000,9140 *$ & $61695,2782^{*}$ & $59171,6365^{*}$ & 46651,1418 & $23636,8170^{*}$ \\
\hline \multicolumn{2}{|l|}{$\mathbf{R}^{2}$} & 0,9924 & 0,9989 & 0,9968 & 0,9966 & 0,9957 & 0,9916 \\
\hline \multicolumn{2}{|l|}{ Média } & 50,44 & 78,70 & 41,49 & 65,04 & 68,12 & 81,21 \\
\hline \multicolumn{2}{|l|}{ Moda } & 39,56 & 66,58 & 33,69 & 55,74 & 59,55 & 70,29 \\
\hline \multicolumn{2}{|l|}{ Mediana } & 46,09 & 74,36 & 38,76 & 61,94 & 65,31 & 77,95 \\
\hline
\end{tabular}

$\mathrm{X}=$ porcentagem de depósito do traçador em relação ao total aplicado; a, b e c são estimativas dos parâmetros do modelo para o traçador. $* *$ significativo a $1 \%$ de probabilidade. 
Pode-se constatar que, as pontas que resultaram nas menores deposições nas folhas e nos perfilhos de capim-colonião (planta inteira) foram aquelas cujo volume de aplicação foi de $100 \mathrm{~L} \mathrm{ha}^{-1}$. Da mesma forma, a ponta TJ60 11002 VS proporcionou maior deposição da calda de pulverização nas folhas e perfilhos de capim-colonião.

Todos os tratamentos apresentaram boa eficiência na dessecação das plantas de $P$. maximum a partir dos 17 DAA, com valores superiores a $85 \%$ de controle (Tabela 6). Após os 21 DAA, todos os tratamentos apresentaram controle superior a $89 \%$. Aos 30 DAA, a dessecação do capim-colonião com diferentes pontas de pulverização, proporcionaram valores satisfatórios, destacando-se a dessecação realizada com a ponta TX-8 VK e volume de $200 \mathrm{~L} \mathrm{ha}^{-1}$, apresentando controle de $98 \%$ das plantas. Ressalta-se que essa ponta foi a que obteve um dos melhores depósitos nas folhas.

Furlanetti et al. (2001), avaliando a deposição de calda de pulverização com um herbicida sistêmico (glyphosate) e um de contato (paraquat), observaram que, com o herbicida sistêmico, os tratamentos que proporcionaram maiores depósitos, promoveram melhor controle das plantas daninhas. Resultados semelhantes foram encontrados por Costa et al. (2008) testando o efeito de pontas de pulverização na deposição e na dessecação de $B$. brizantha com glyphosate, onde avaliaram diferentes vazões e tamanho de gotas na deposição. Esses autores afirmaram que todas as pontas foram eficientes na dessecação das plantas, independentemente do volume e ponta utilizados, evidenciando a possibilidade de redução do volume aplicado na dessecação de pastagens.

Com relação aos dados de matéria seca (Tabela 6), todos os tratamentos proporcionaram reduções superiores a $60,7 \%$, sendo que a menor redução foi obtida quando a dessecação foi realizada com a ponta XR 11002 VS, no volume de calda de $200 \mathrm{~L} \mathrm{ha}^{-1}$. A maior redução foi proporcionada utilizando-se a ponta XR 11001 VS e volume de calda de $100 \mathrm{~L} \mathrm{ha}^{-1}$. É importante ressaltar, que o controle da espécie tanto nas avaliações visuais como na matéria seca ao final do experimento não detectaram diferenças entres os tratamentos. Este fato pode ser consequência da alta dose de glyphosate utilizada, não permitindo evidenciar as vantagens da maior deposição alcançada pela ponta TJ 11002 VS nas folhas e perfilhos de capim-colonião.

Segundo Ferreira et al. (2000), o sucesso da dessecação consiste em uma cobertura mínima, uniforme e de elevada qualidade. Esta condição está diretamente relacionado com o diâmetro das gotas, que também estabelece o seu comportamento quanto à distância de deslocamento (deriva), à penetração na folhagem, à perda por evaporação e, consequentemente, à taxa de recuperação. Dessa forma, torna-se fundamental a utilização de pontas de pulverização que proporcionem maior deposição da calda e de maneira uniforme no alvo, para evitar que algumas plantas daninhas não sejam atingidas pelas gotas pulverizadas, bem como a cultura a ser manejada. 
Tabela 6 - Porcentagem de controle e matéria seca de plantas de Panicum maximum cv. Mombaça, dessecadas com diferentes pontas de pulverização.

\begin{tabular}{|c|c|c|c|c|c|c|c|}
\hline Tratamentos & $\begin{array}{l}\text { Volume } \\
\left(\mathrm{L} \mathrm{ha}^{-1}\right)\end{array}$ & 4 DAA & 11 DAA & 17 DAA & 26 DAA & 30 DAA & $\begin{array}{c}\begin{array}{c}\text { Matéria seca } \\
\left(\mathrm{kg} \mathrm{ha}^{-1}\right)\end{array} \\
\end{array}$ \\
\hline $\begin{array}{l}\text { Testemunha } \\
\text { X R } 11001 \mathrm{VS}\end{array}$ & 100 & $22 \mathrm{a}$ & & & & & $\begin{array}{l}4431 \mathrm{a} \\
1767 \mathrm{~b}\end{array}$ \\
\hline${ }_{-}^{\mathrm{X}} \mathrm{R} 11002 \mathrm{~V} S$ & 200 & $10 \mathrm{ab}$ & 80 & 88 & 92 & $9 \overline{4}$ & $2691 \mathrm{~b}$ \\
\hline TX-4VS & 100 & $9 \mathrm{ab}$ & 71 & 85 & 90 & 90 & $2387 \mathrm{~b}$ \\
\hline TX-8 VK & 200 & $1 \mathrm{c}$ & 90 & 97. & 99. & 98 & $2109 \mathrm{~b}$ \\
\hline $\bar{A} \bar{I} 1 \overline{1} 1002 \overline{V S}$ & $200^{-}$ & $\overline{4} \overline{\mathrm{bc}}$ & $\overline{7} \overline{7}$ & 87 & 89 & $\overline{8} \overline{6}$ & $\overline{2} \overline{4} \overline{6} \bar{b}$ \\
\hline TJ60 $11002 \mathrm{VS}$ & 200 & 9 bc & 79 & 92 & 97 & 96 & $2002 \mathrm{~b}$ \\
\hline $\mathrm{F}_{\text {Tratamento }}$ & & $0,01^{*}$ & $0,43^{\mathrm{ns}}$ & $0,17^{\mathrm{ns}}$ & $0,16^{\mathrm{ns}}$ & $0,48^{\text {ns }}$ & $0,02^{*}$ \\
\hline $\mathrm{F}_{\text {Bloco }}$ & & $0,13^{\mathrm{ns}}$ & $0,26^{\mathrm{ns}}$ & $0,28^{\mathrm{ns}}$ & $0,58^{\mathrm{ns}}$ & $0,76^{\mathrm{ns}}$ & $0,97^{\mathrm{ns}}$ \\
\hline $\mathrm{CV}(\%)$ & & 48 & 15 & 10 & 10 & 12 & 40 \\
\hline
\end{tabular}

Dados de porcentagem foram transformados em arco seno $\sqrt{ } \mathrm{x} / 100$.

Médias seguidas de mesma letra na coluna, não diferem estatisticamente entre si, pelo teste “LSD” ( $p>0,05)$.

** - significativo a $1 \%$;

ns - não significativo.

DAA - Dias Após a Aplicação

Segundo Gazziero et al. (2006), a Dessa forma, devem ser realizados variação da deposição pode está relacionada mais estudos nessa área que avaliem a deposição com a diferença de tamanho e o estádio de de gotas com herbicidas sistêmicos, além de desenvolvimento das plantas, sugerindo uma novas pontas de pulverização que permitam a tendência de maiores irregularidades em redução do volume de aplicação sem prejudicar períodos diferenciados. Knoche (1994) observou a distribuição das gostas no alvo e que que, diminuindo-se o tamanho da gota e minimizem as perdas por deriva. aumentando a cobertura, melhora o desempenho dos herbicidas sistêmicos em $76 \%$ dos experimentos, mais freqüentemente do que em herbicidas de contato (58\% dos experimentos). 

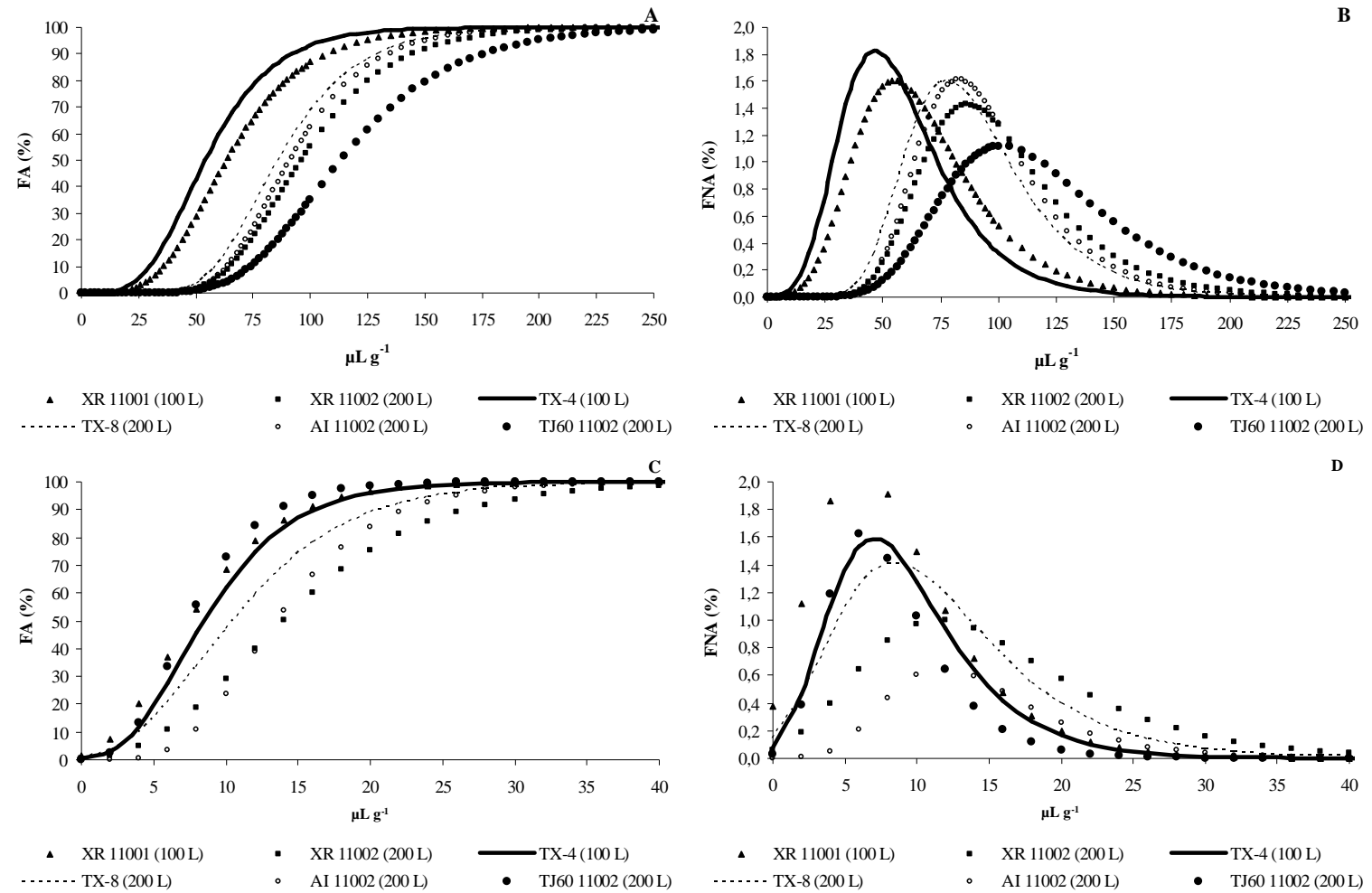

- XR $11001(100 \mathrm{~L}) \quad$ - XR $11002(200 \mathrm{~L})$ . - TX-8 $(200 \mathrm{~L}) \quad$ A $11002(200 \mathrm{~L})$
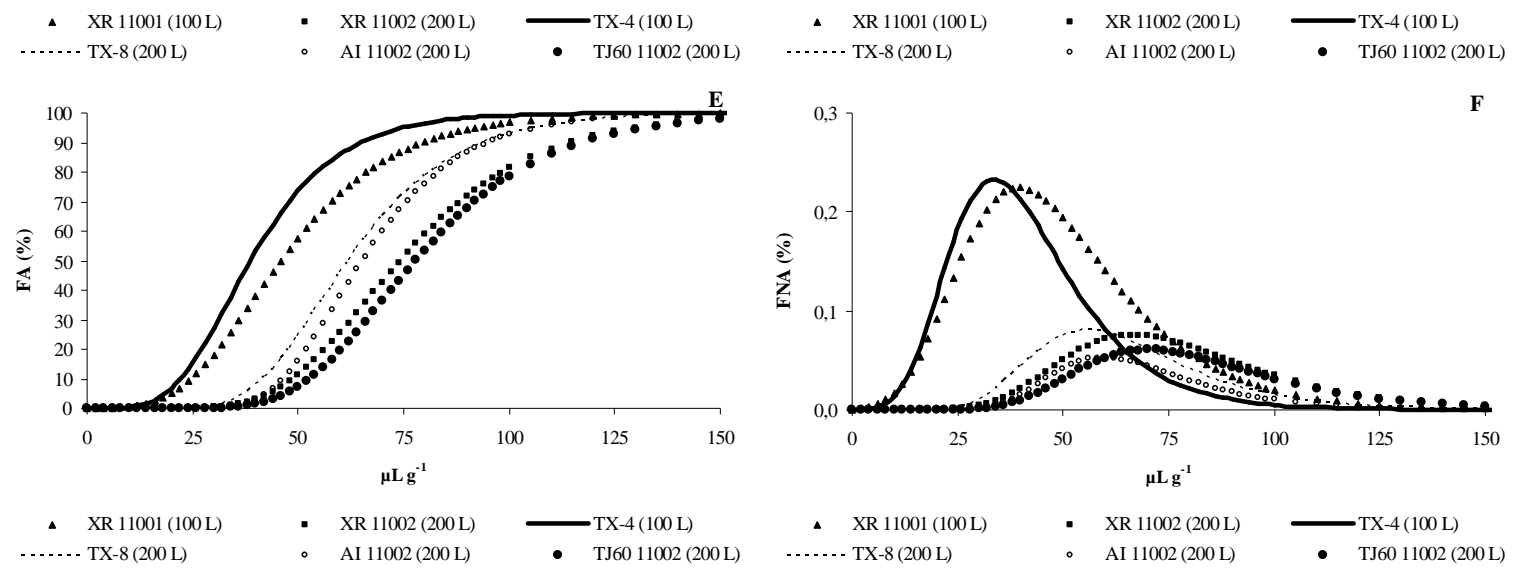

Figura 1 - Frequência acumuladas (FA\%): (A, C e E), e não-acumuladas (FNA\%): (B, D e F), em função da deposição da calda de pulverização em $\mu \mathrm{L} \mathrm{g}^{-1}$ de massa seca de folhas (A e B), caule (C e D) e perfilho (E e F) de Panicum maximum cv. Mombaça.

\section{Conclusões}

Com base nos resultados obtidos pode concluir que, as pontas e volume de aplicação utilizados proporcionaram eficiente manejo de dessecação das plantas de $P$. maximum cv.
Mombaça com o herbicida glyphosate, este fato, indica a possibilidade de redução do volume de aplicação na dessecação dessa espécie, considerando a utilização de herbicidas sistêmicos. Entretanto, a ponta TX4 VS (100 $\mathrm{L} \mathrm{ha}^{-1}$ ) promoveu a melhor 
uniformidade de depósitos na planta inteira, enquanto que, a ponta TX-8 VK (200 L ha $\left.{ }^{-1}\right)$, proporcionou menor deposição de calda no solo.

\section{Referências}

AGAIRUPDATE. El sistema de pulverización electrostática trae carga a la aviación agrícola. AgAirUpdate Latinoamerica, v.3, n.3, p.14-15, 2000 .

CORDEIRO, A. M. C. Como a tecnologia de aplicação de produtos fitossanitários pode contribuir para o controle de pragas, doenças e plantas daninhas. In: ZAMBOLIM, L. Manejo integrado: fitossanidade, cultivo protegido, pivô central e plantio direto. Viçosa, MG: Universidade Federal de Viçosa, 2001. p. 683-721.

COSTA, N. V. et al. Efeito de pontas de pulverização na deposição e na dessecação em plantas de Brachiaria brizantha. Planta Daninha, v.26, n.4, p.923-933, 2008.

FERREIRA, G. A. et al. Comparação de bicos de pulverização na dessecação do milheto (Pennisetum americanum). Pesquisa Agropecuária Tropical, v.30, n.1, p.65-70, 2000.

FURLANETTI, A. C., MATUO, T. e BARBOSA, J. C. Uniformidade de deposição da calda de pulverização de herbicidas em barra lateral protegida com diferentes combinações de pontas de pulverização. Planta Daninha, v.19, n.3, p.445-456, 2001.

GALON, L. et al. Controle de plantas daninhas e seletividade de herbicidas à cultura da soja, aplicados em dois volumes de calda. Revista Brasileria de Agrociencia, v.13, n.3, p.325-330,

GAZZIERO, D. L. P. et al. Deposição de Glyphosate aplicado para controle de plantas daninhas em soja transgenica. Planta Daninha, v.24, n.1, p.173-181, 2006.

KNOCHE, M. Effect of droplet size and carrier volume on performance of foliage-applied herbicides. Crop Protection, v.13, n.3, p.163-178, 1994.

KOZLOWSKI, L. A. Aplicação seqüencial de herbicidas de manejo na implantação da cultura do feijoeiro comum em sistema de plantio direto. Revista Brasileira de Herbicida, v. 2, n. 1, p. 4956, 2001.

MACIEL, C.D.G.; VELINI, E.D.; BERNARDO, R.S. Desempenho de pontas de pulverização em Brachiaria brizantha cv. MG-4 para controle de ninfas de cigarrinhas das pastagens. Engenharia Agrícola, v.27, n.esp., p.66-74, 2007.

PALLADINI, L. A., RAETANO, C.G., VELINI, E. D. Choice of tracers for the evaluation of spray deposits. Scientia Agricola, v.62, n.5, p.440-445, 2005.

RODRIGUES, A.C.P. et al. Variáveis qualitativas da pulverização em feijão, Bidens pilosa e Brachiaria plantaginea. Ciência e Agrotecnologia, v.34, n.3, p. 698-707, 2010.

RODRIGUES, B. N.; ALMEIDA, F. S. Guia de herbicidas. 5. ed. Londrina: Grafmarke, 2005. 591 p.

RUAS, R.A.A. et al. Estimativa de parâmetros técnicos da tecnologia de aplicação do glyphosate no controle de Brachiaria decumbens. Revista Ceres, v.58, n.3, p. 299-304, 2011.

SOCIEDADE BRASILEIRA DA CIÊNCIA DAS PLANTAS DANINHAS - SBCPD. COMITÊ BRASILEIRO DE RESISTÊNCIA DE PLANTAS AOS HERBICIDAS. Identificação e manejo de plantas daninhas resistentes aos herbicidas. Londrina: 2000. 32 p.

SOUZA, L.A.; CUNHA, J.P.A.R.; PAVANIN, L.A. Deposição do herbicida 2,4-D Amina com diferentes volumes e pontas de pulverização em plantas infestantes. Revista Ciência Agronômica, v.43, n.1, p.78-85, 2012.

SOUZA, R.T. et al. Aspectos metodológicos para análise de depósitos de pulverizações pela determinação dos depósitos pontuais. Planta Daninha, v.25, n.1, p.195-202, 2007. 
VELINI, E. D. Estudos e desenvolvimento de métodos experimentais e amostrais adaptados à matologia. Jaboticabal, SP, 1995. 250p. Tese (Doutorado em Agronomia/Produção Vegetal) Faculdade de Ciências Agrárias e Veterinárias, Universidade Estadual Paulista.

VENTURELLI, L. et al. Cobertura y respuesta biológica del glyphosate ante la utilización de distintas pastillas de pulverización. In: XXXV Congresso Brasileiro de Engenharia Agrícola, João Pessoa. Anais do XXXV Congresso Brasileiro de Engenharia Agrícola- CD-Rom. Jaboticabal : SBEA, 2006. p.67-68.

VIANA, R.G. et al. Características técnicas de pontas de pulverização LA-1JC e SR-1. Planta Daninha, v.25, n.1, p.211-218, 2007. 